\title{
RHEOLOGICAL CHARACTERISTICS OF THERMOPLASTIC POLYMERS AFTER DEGRADATION
}

Selected rheological properties of thermoplastic polymer materials before and after exposure in different environments were evaluated by Frequency sweep test, which monitors changes in viscoelastic properties of polymers with respect to their molecular structure and their behavior in thermoplastic processes. Samples of tested material were subjected in UV radiation, moist soil with higher concentration of chlorides and solution of n-hexane for exact period. Degradation process resulted in changes of complex dynamic viscosity, storage and loss modulus, changes in molar mass and its distribution.

\section{Introduction}

In the last few decades, polymers have been widely used materials in industry and their utilization in engineering applications is widely growing all over the world. Their versatility makes them suitable for a whole range of applications, and comes from the capability of manufacturers to tailor microstructures and properties through control of the processing conditions [1].

Polymer materials represent an important area in which they are becoming predominant against other materials and have increased considerably and rapidly. Their relatively low cost, ease of installation, transportation, and long-term durability against environmental degradation (harmful environmental attack such as corrosion, rust and higher thermal stresses) make plastics an attractive alternative to metals. Among the most common polymers utilized in such applications are polyethylene (PE) and polypropylene (PP) [2].

Rheology and its experiments reveal information about the flow behavior of liquids but also the deformation behavior of solids, because it is the typical behavior of polymers. Changes induced by the environment with degradation effect can be evaluated by rheological measurements which monitor changes in viscoelastic properties of the tested polymers. The fundamental of rheological characteristics is viscosity which defines the internal resistance of material against its creep generated by external forces [3, 4]. It is necessary to realize the dual character of majority of polymer materials from viscoelastic point of view. The action of external force on the ideal viscous material results in its deformation i.e. irreversible locomotion (movement) of macromolecules and after removal of the external force material retains its "new" shape. The action of external force on the ideal elastic material results in its deformation but after the removal of the external force, the material returns to its original shape. Polymers are generally characterized by the viscoelastic nature, which means that external forces cause partly permanent (viscosity element of polymer) and partly reversible (elastic element of polymer) deformation $[5,6]$.

Viscosity has a high importance for polymer processing, the change of viscosity is determined by changes of particular factors (temperature, pressure, molecular weight and its distribution, structure of the polymer, presence of additives in the polymer), which are characteristic for the polymer and may vary according to the effect of degradation processes [7].

The aim of this study is the comparison of selected rheological properties of thermoplastic polymer materials before and after exposure in different environments with a degradation effect.

\section{Experimental material and conditions of preparation}

The polymers used in this study are commercially available and provided in the form of pellets by the plastics company Nitra and Licharz company. Polyethylene PE 1400 with the trade name Finathene XS 10 YCF S 70111902, high density, low pressure PE 500 with the trade name PE HMW, and polypropylene PP was used as an experimental material.

These thermoplastics materials pose very good chemical resistance, relatively low density $0.91-0.96 \mathrm{~g} / \mathrm{cm}^{3}$, low absorption, good resistance at high negative temperature, good workability and some other properties like coefficient of friction, abrasion resistance and impact toughness [5].

Polymer samples of plate shape with dimension of $10 \times 55 \times$ $3 \mathrm{~mm}$ were exposed in different environments with degradation

\footnotetext{
* Michaela Vojsovicova, Tatiana Liptakova, Viera Zatkalikova

Department of Materials Engineering, Faculty of Mechanical Engineering, University of Zilina, Slovakia,

E-mail: michaela.vojsovicova@fstroj.uniza.sk
} 
effect. Samples of PP and PE 500 were exposed to aliphatic hydrocarbon n-hexane, immersed in a separated container for 3 and 6 months at laboratory temperature. PE 1400 samples were subjected to long-term (485 days) exposure in moist soil with high chloride concentration simulating conditions of the real working environment. Accelerated aging tests of PE 1400 samples were carried out in UV chamber for a period of 139 days, which represents 700 cycles and intake energy of $5264 \mathrm{kJm}^{-2}$. One cycle in the UV chamber is represented by 4.8 hours of testing with delivered energy of about $7.52 \mathrm{kJm}^{-2}$ per cycle. Daily cycle runs for 3.8 hour (temperature of $62 \pm 3^{\circ} \mathrm{C}$; relative humidity of $50 \pm 5 \%$; intensity of radiation $0.55 \mathrm{Wm}^{-2}$ ) and 1 hour night cycle (temperature of $38 \pm 3^{\circ} \mathrm{C}$; relative humidity of $50 \pm 5 \%$; intensity of radiation $0 \mathrm{Wm}^{-2}$ ).

\section{Measuring technology and interpretation of used method}

The evaluation of polymer degradation was performed by measuring of rheological properties by oscillating rheometer Physica Rheometer MCR 301 with the Convection Temperature Device CTD 450, a unique chamber that offers gradient free measurements and a direct measure of the sample temperature. The sample temperature equals the sensor temperature at any time. The chosen method was Frequency Sweep test (FS), which characterizes the viscoelastic properties of polymers with respect to their molecular structure and their behavior in thermoplastic processes [4, 8].

The sample thermoplastic polymer was placed between two parallel plates with diameter of $25 \mathrm{~mm}$ at a gap of $1 \mathrm{~mm}$. Measurements were carried out at the temperature of $160{ }^{\circ} \mathrm{C}$ and $180{ }^{\circ} \mathrm{C}$, according to the nature of the material and following conditions: an amplitude of $\gamma=5 \%$, an angular frequency of $\omega=500-$ $0.051 / \mathrm{s}$.

The principle of material evaluation is based on evaluation of measured parameters which are shown in the diagram (Fig. 1). The process of degradation is followed by changes of molecular mass (as networking or macromolecular chains breaking) which should be reflected in the measured parameters.

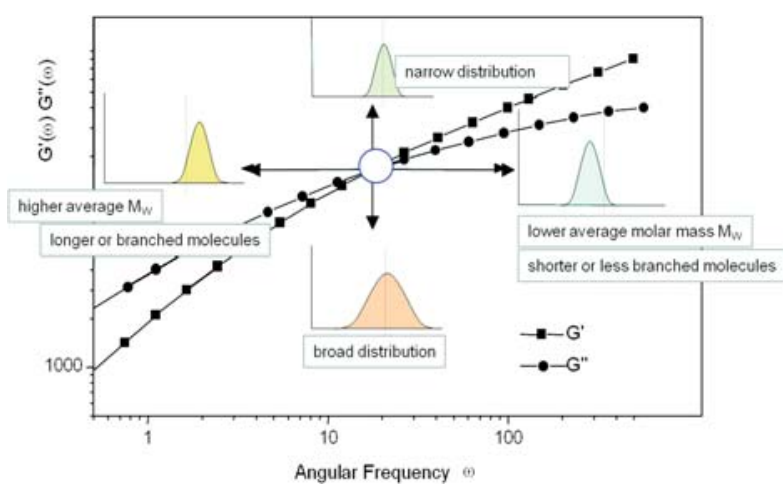

Fig. 1 Determination of selected rheological characteristics $G^{\prime}, G^{\prime \prime}$ of material during FS test
The analysis of the cross-over point (COP) between the storage modulus $G^{\prime}$ and the loss modulus $G^{\prime \prime}$ in the frequency sweep, as seen in Fig. 1, makes it possible to obtain the qualitative picture of the average molar mass and molar mass distribution. Furthermore, we are able to monitor the position of the intersection of the curves characterizing the state of both modulus and indicate the transition from viscous deformation behavior to the more elastic behavior. This COP is qualitative characteristics of the material [9]. The polymer degradation can result in changes of the values of measured characteristics. Shift of the COP in horizontal direction provides information about the average molar mass and shift of the COP in the vertical direction signals the difference in the molar mass distribution.

\section{Results and discussion}

The degradation of PE 1400 after exposure in UV chamber (after 700 cycles) was evaluated by Frequency Sweep test (FS). The differences in viscosity and modulus defining plastic and elastics properties of PE samples are shown in Fig. 2. These measurements were carried out only in exposed surface layers that were replaced from the exposed sample (in depth of 0 to $750 \mu \mathrm{m}$ and 750 to $1500 \mu \mathrm{m})$. There is evident difference in degradation seen from the surface further to the depth and the layer of $750 \mu \mathrm{m}$ has significantly different viscoelastic properties - material becomes more fragile. Measurement of the sample layer in the depth of $750-1500 \mu \mathrm{m}$ showed that the degradation is much smaller and measured curve is closer to the curve of unaffected sample.

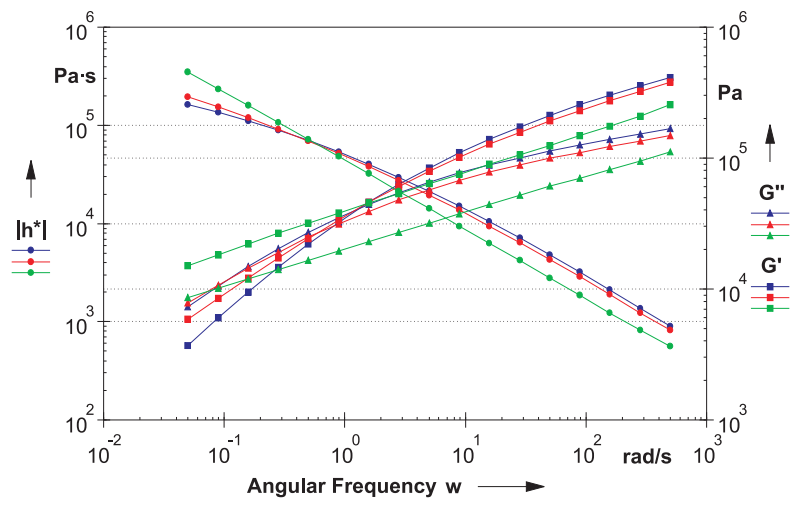

PE 1400 before exposure, PE 1400 in UV (0 - $750 \mu m)$, PE 1400 in UV (750 - $1500 \mu \mathrm{m})$

Fig. 2 Rheological properties of PE 1400 after 700 cycles in UV test

Moist soil with higher concentration of chlorides had no significant degradation influence on PE 1400 even after long-term exposure. Fig. 3 shows that polyethylene material was not damaged in surface layers which was verified by measuring replaced layers in particular depth $(0-750 \mu \mathrm{m}$ and $750-1500 \mu \mathrm{m})$ from surface area. According to the results it is clear that neither surface 


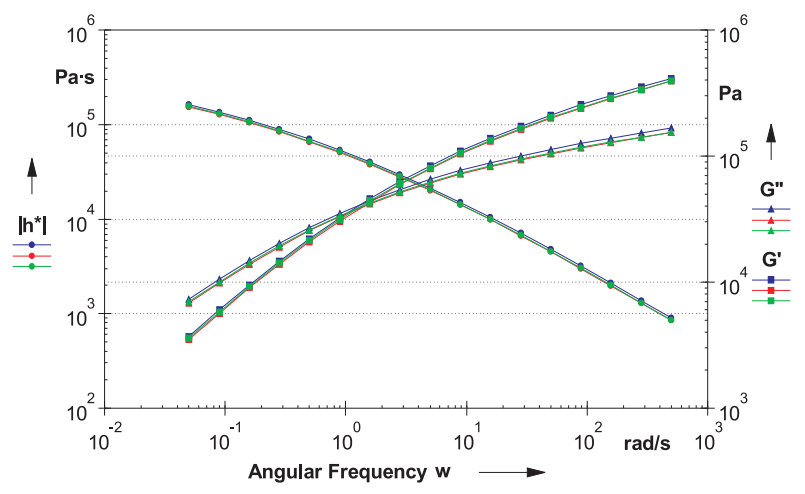

PE 1400 before exposure, PE 1400 in moist soil (0 - $750 \mu m)$, PE 1400 in moist soil (750 - $1500 \mu \mathrm{m})$

Fig. 3 Rheological properties of PE 1400 after 485 days in moist soil

areas nor subsurface areas were influenced by degradation effect because the values of measured variables indicate almost the same course.

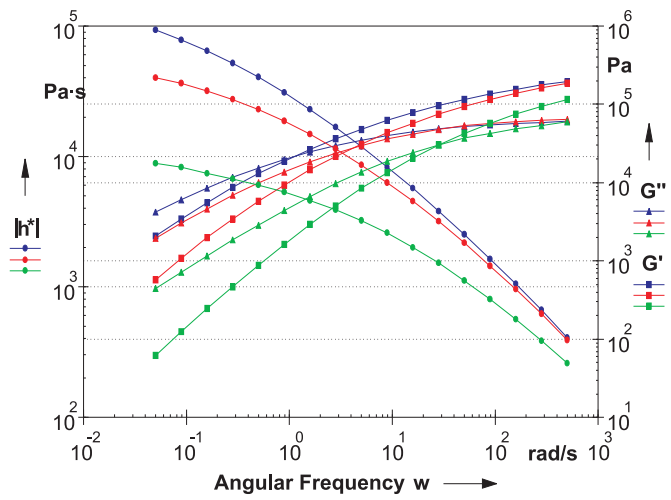

Measurements of PP and PE 500 exposed in n-hexane for period of 3 months (Figs. 4 and 5) and 6 months (Figs. 6 and 7) show the changes of viscosity, as well as $G^{\prime}$ and $G^{\prime \prime}$ modulus in both surface layers but only in PP samples. PE 500 indicates no changes in viscoelastic properties in comparison with the original material. We can monitor that the area in the depth of 300-600 $\mu \mathrm{m}$ is affected more than the surface layer of $0-300 \mu \mathrm{m}$, in which material properties are much more similar to properties of unexposed material. This phenomenon is not very clear to explain yet and is subjected to further study.

\section{Conclusion}

- Changes in the structure of studied polymers due to degradation effect in different environment can be sensitively monitored by rheological measurements. This was reflected in the measured rheological parameters and variables like viscosity, molecular mass and its distribution, modulus characterizing elastic and plastic properties.

- The results prove that the exposure of PP and PE 500 in nhexane only influenced the degradation of PP samples which

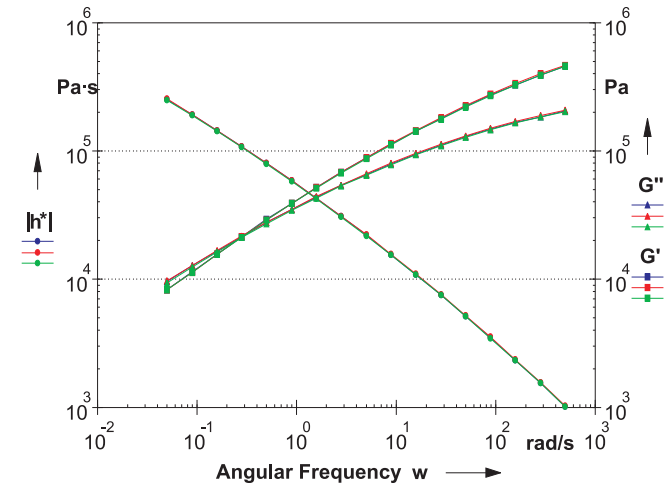

PP before exposure, PP 500 exposed in $n$-hexane $(0-300 \mu \mathrm{m})$, PP 500 exposed in $n$-hexane $(300-600 \mu \mathrm{m})$ PE 500 before exposure, PE 500 exposed in $n$-hexane $(0-300 \mu \mathrm{m})$, PE 500 exposed in $n$-hexane (300 - $600 \mu \mathrm{m})$

Figs. 4 and 5 Rheological properties of PP and PE 500 exposed in n-hexane for 3 months
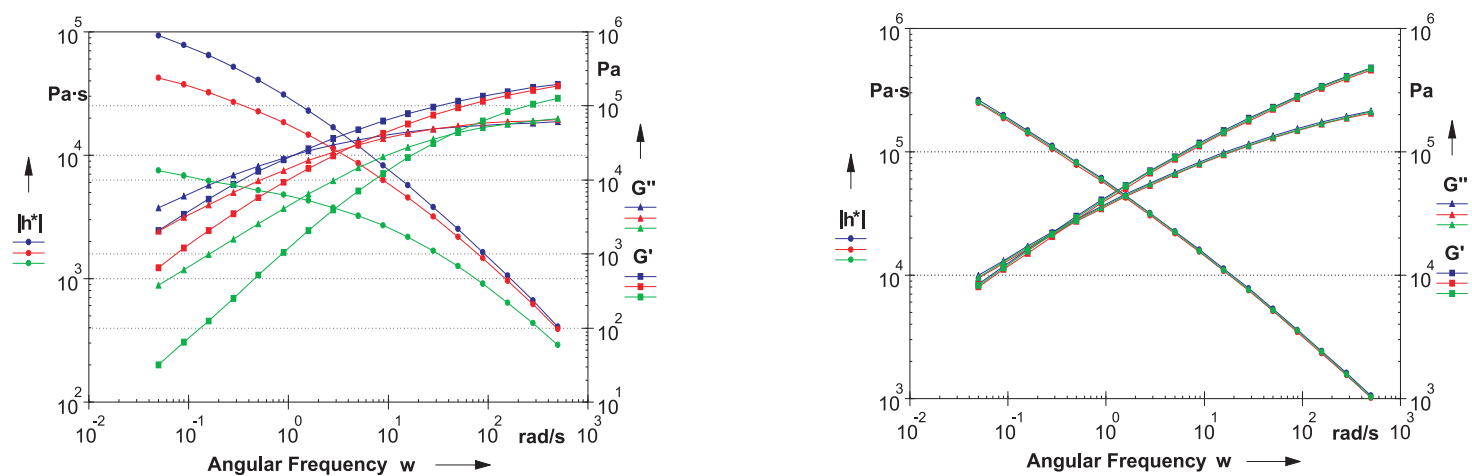

PP before exposure, PP in n-hexane (0 - $300 \mu \mathrm{m})$, PP in n-hexane (300 - $600 \mu \mathrm{m})$

PE 500 before exposure, PE 500 in n-hexane (0 - $300 \mu \mathrm{m})$, PE 500 in n-hexane (300 - $600 \mu \mathrm{m})$

Figs. 6 and 7 Rheological properties of PE and PE 500 exposed in n-hexane for 6 months 
varied in particular layers. The rheological characteristics of polyethylene material stay unchanged.

- The long-term exposure of PE 1400 in moist soil had no significant effect on viscoelastic characteristics of tested material.

\section{Acknowledgements}

This study has been supported by the Scientific Grant Agency of Ministry of Education, Science, Research and Sport of the Slovak Republic and Slovak Academy of Science, grant No. 1/0066/11.

\section{References}

[1] MENDELL, J. F., ROBERTS, D. R., MGARRY, F. J.: Plane Strain Facture Toughness of Polyethylene Pipe Materials, In: Polym Eng Sci 23, 1983, pp. 615-651.

[2] MOURAD, I. A-H.: Thermo-mechanical Characteristics of Thermally Aged Polyethylene/Polypropylene Blends, In: Materials \& Design 31, 2010, pp. 918-929.

[3] MEZGNER, T. G.: The Reology Handbook, $2^{\text {nd }}$ Edition, ISBN 3-87870-174-8, Hannover 2006, pp. 299.

[4] WOLLNY, K.: Comparison of Polyethylene, Melts Using Frequency Sweeps, Anton Paar, Germany, GmbH 2003.

[5] LIPTAKOVA, T., ALEXY, P., GONDAR, E., KHUNOVA, V.: Polymer Technological Materials (in Slovak), EDIS ZU, Zilina, 2009, pp. 5-7.

[6] CARRAHER, CH. E. Jr.: Introduction to Polymer Chemistry, Taylor and Francis Group, ISBN 0-8493-7047-2, USA, 2007.

[7] VOJSOVICOVA, M., LIPTAKOVA, T., GANA, D.: Evaluation of Rheological Properties of Thermoplastic Polymers after Degradation, Transcom 2011, $9^{\text {th }}$ European Conference, Zilina, 2011

[8] Anton Paar Application specific documents, available online at http://www.anton-paar.com/MCR-Rheometer-Series/Rheometer/ 60_Corporate_en?product_id=45\#Downloads.

[9] WOLLNY, K.: Comparison of a Propylene Reinceforced with Glass Fiber and Pure Polypropylen over a Temperature Range from - 150 to $+180{ }^{\circ} \mathrm{C}$, Anton Paar, Germany GmbH 2006. 